\title{
Adapting to climate change: Are people willing to pay or change?
}

\author{
$\underline{\text { L.J.L. Veldhuizen }}^{a}$, S. Tapsuwan $^{b}$ and M. Burton ${ }^{c}$ \\ ${ }^{a}$ Wageningen University, ${ }^{b}$ Commonwealth Scientific and Industrial Research Organization, ${ }^{c}$ University of \\ Western Australia.
}

\begin{abstract}
Most urban and suburban households in Australia are not particularly vulnerable to climate change (as long as they are not in flood prone areas or are by the beach). When households do not perceive that they are vulnerable, they have less incentive to take any mitigation or adaptation actions against climate change. In reality, everyone will be affected by climate change because pricing of externalities (ie. carbon tax) will make everything more expensive. In light of this, what would households prefer to do? Would they choose to change their behaviours (e.g. drive less, turn off lights) to reduce carbon emissions in order to help the country reach its emission target, or would they prefer to pay the government (e.g. in the form of an income tax) so that they do not have to change their daily behaviours. How do these preferences vary with political preferences? A choice experiment survey was conducted to elicit households' willingness to pay for a number of climate change related policies. Results from a pilot survey of 100 households in Australia suggest that political party preference has a significant impact on household preference for climate change policy. Liberal party voters are averse to the carbon tax while non-Liberal party voters show support for carbon tax over a general income tax.
\end{abstract}

Keywords: choice experiment, WTP, climate policy, carbon tax, climate change 


\section{INTRODUCTION}

The climate change issue first appeared on Australia's political agenda when in 2002 John Howard's liberal government announced it would support and ratify the Kyoto Protocol. On June 5 of that year, however, the Howard government announced not to ratify the Protocol as a result of strong opposition by the coal industry. The 2007 elections brought about a change as Kevin Rudd's Labour Party ratified the Kyoto Protocol in 2007 and in 2008 announced the introduction of an emissions trading scheme (ETS). However, strong opposition in parliament forced Kevin Rudd in 2009 to put the ETS on hold. Then in 2010, just weeks before the new elections, Labor candidate Julia Gillard made the promise that: "[ $\mathrm{t}]$ here will be no carbon tax under the government I lead." However in February 2011, Gillard's government announced its plans for the introduction of a carbon tax. A carbon tax that should ultimately lead to the introduction of an ETS in 2015-2017.

These continuous political shifts on the climate change issue indicate that strong disagreement exists among the public's representatives and among the public. The question is whether this disagreement can solely be attributed to disagreement on climate change mitigation, or whether the mitigation policies under discussion also contribute to this disagreement. Therefore, the main goal of this study is to study the influence of the specific policy on willingness to pay (WTP) for climate change mitigation.

To elicit WTP estimates, a choice modeling (CM) survey has been conducted throughout Australia in July 2011. The basis for this survey lied in the literature review that will be discussed in section 2 . In section 3 , the methodology of this study will be discussed, where a detailed explanation will be provided of this study's model, survey and survey sample. Section 4 will describe the main results of this study. Finally, section 5 provides the main conclusion and recommendations based on the results of this study.

\section{LITERATURE REVIEW}

Three approaches to studying WTP for climate change mitigation that have been used over the last decade form the basis of this study. A first method, employed by Berk and Fovell (1999) has been to use temperature changes to illustrate the effects of climate change. Results from this study indicated that an individual's WTP does not only depend on the impacts of climate change at an individual level, but also on impacts on a broader scale. Therefore, this study has been performed at a national level taking into account regional differences.

A second method used by Carlsson et al. (2010) has been to present both temperature changes and flow-on effects in one table to illustrate the different impacts of three mitigation scenarios: $85 \%$ reduction, $60 \%$ reduction and $30 \%$ reduction. The advantage of this approach is that the complex issue of climate change mitigation with its different impacts on temperature changes, harvests, extreme weather events and ecosystems is visualized in a comprehensive yet concise manner. Therefore, a similar approach has been developed for this study.

A third approach to WTP for climate change mitigation has been to study the influence of a mitigation policy's implementation details and distributional effects on WTP for such a policy. Carson et al. (2010) studied the importance of implementation details and found that such details matter to people, however, opinions (support or oppose taking action about climate change) have an effect on people's perception of the relative importance of the detail. Lee and Cameron (2008) and Cai et al. (2010) studied the influence of distributional effects of different mitigation policies on WTP. Cai et al. (2010) found that people have a lower WTP for policies where the poor were perceived to be paying a disproportionate part of the costs. Also, the public's WTP was lower when other countries did not contribute to global climate change mitigation (Lee and Cameron, 2008). The results of Carson (2010), Cai et al. (2010) and Lee and Cameron (2008) show that policy details have their effect on WTP for climate change mitigation.

Therefore, this national study will focus on the influence of policies regarding fuel levy, petrol levy, income tax and carbon tax; the uses of revenues from these policies for $R \& D$ for climate change mitigation, income subsidies for lower income households and seniors and increased funding for public services; the emission level low and medium; and the monthly cost levels 10, 20, 50, 75, 100 and 150 AUD. The survey will include explanations and illustrations on the impacts of climate change on future expected temperatures, rainfall, number of hot days, freshwater supplies, wildfires, crop yield, cyclones and ecosystem losses. The results presented in this paper are from the preliminary design of the national survey.

\section{METHODOLOGY}

The methodology employed in this study consists of three elements. First, a model was specified to serve the goal of this study. Second, a survey was designed based on this model, in line with the approach of this study. Third, a survey sample was drawn and the survey was distributed among respondents in this sample. 


\subsection{Model specification}

WTP studies commonly utilize either revealed preference (RP) or stated preference (SP) data (Bateman et al., 2002; Bennett and Blamey, 2001). In this specific study the focus lies on preferences for mitigation policies, for which no RP data exists. Therefore, this study uses data from an SP survey. The methods that have been used most commonly in SP studies on climate change are the contingent valuation method (CVM) and choice modeling (CM). Due to an interest in the tradeoffs people make between different policy details, the most suitable method for this study is CM (Bennett and Blamey, 2001).

In such a study, people are presented with a fixed number of choice sets that contain a specified number of options. Each option is described by a set of attributes and a payment vehicle. Various levels are assigned to the attributes in the different choice sets to represent the range of variation in that attribute that is of interest for the research goal of the study (Bennett and Blamey, 2001). Respondents are asked to select their preferred option in each choice set they are presented with. These responses form the core part of SP data from a CM survey.

Daniel McFadden's (1974) random utility theory (RUT) forms the basis of CM. The basic premise of RUT is that a diverse population of individuals shares a common decision rule. Still, a random component remains due to random errors and variations at the individual level (McFadden, 1974). Thus, within a population:

$$
U=V(i, j)+\varepsilon(i, j),
$$

where utility $U$ comprises of a non-stochastic element $V$ that reflects the representative tastes of a population and a stochastic element $\varepsilon$ that reflects the random component of a population (McFadden, 1974). The elements $V$ and $\varepsilon$ depend on a number of characteristics $i$ of the individuals and a number of attributes $j$ of the object of this utility function. The functional form for utility given in (1) consists of an observed $V(i, j)$ and an unobserved or random element $\varepsilon(i, j)$. This observed element $V(i, j)$ can be further specified (McFadden, 1974):

$$
v(i, j)=\theta_{1} v^{1}(i, j)+\ldots+\theta_{K} v^{K}(i, j),
$$

where $v^{K}(i, j)$ are specified numerical functions and where $\theta_{K}$ are unknown parameters.

Therefore, the utility function for this study is specified as:

$$
V_{i j}=S Q_{j}+\sum \beta_{p}\left(\text { Policy }_{j p}\right)+\sum \beta_{R}\left(\text { Revenue }_{j R}\right)+\sum \beta_{E}\left(\text { Emission }_{j E}\right)+\sum \beta_{S}\left(S Q_{j} * L_{i}\right)+\beta_{C}\left(\text { Cost }_{j}\right),
$$

where

$S Q_{j} \quad$ Status quo dummy variable $(\mathrm{SQ}=1$ for the status quo option and $\mathrm{SQ}=0$ otherwise)

Policy $_{j p} \quad$ Policy attribute

Revenue $_{j R} \quad$ Use of government revenue

Emission $_{j E} \quad$ Emission level

$L_{i} \quad$ Voting preference, $L_{i}=1$ if the individual will vote for the Liberal party in the next election, 0 otherwise

Cost $_{j} \quad$ Monthly net cost

and $\beta_{p}, \beta_{R}, \beta_{E}, \beta_{S}, \beta_{C}$ are vectors of parameters

\subsection{Questionnaire design}

Findings from the literature review and exploratory focus groups were used to guide the design of the CM survey. An online survey was conducted in July 2011 as the mode of distributing the questionnaires. The first section of the questionnaire introduced respondents to climate change, its direct impacts on climate conditions and its flow-on effects. Scientific information of projected climate change impacts were provided to reduce confounding effects in the responses caused by individual perceptions of what may be the project impact of climate change in the future. To accommodate for respondents' alternative views on climate change, questions were asked on climate change beliefs (e.g. 'Do you believe that the climate is changing?' 'And do you believe that climate change is caused by human activities?). To assure that respondents answered from a similar knowledgebase, three emission levels were used to explain different effects of climate change (Garnaut, 2008):

○ Low emissions (aiming for 450 ppm CO2-e ${ }^{1}$ in 2100),

\footnotetext{
${ }^{1} \mathrm{CO} 2$-e is Carbon dioxide equivalent: a unit of measurement to indicate a gas's global warming potential relative to $\mathrm{CO} 2$ (Dunlop 2007).
} 
- Medium emissions (aiming for 550 ppm CO2-e in 2100) and

○ High emissions (exceeding 1000 ppm CO2-e in 2100)

The various impacts of these three emission scenarios were illustrated through tables on temperature changes (see

Figure 1 Temperature changes under the low, medium and high emissions scenario.), rainfall changes and changes in the number of hot days in 2050. For each table city summaries were provided for Adelaide, Alice Springs, Brisbane, Cairns, Canberra, Darwin, Hobart, Melbourne, Perth and Sydney. Then, five statements on changes occurring to freshwater supplies, wildfires, crop yield, cyclones and ecosystem losses due to increased

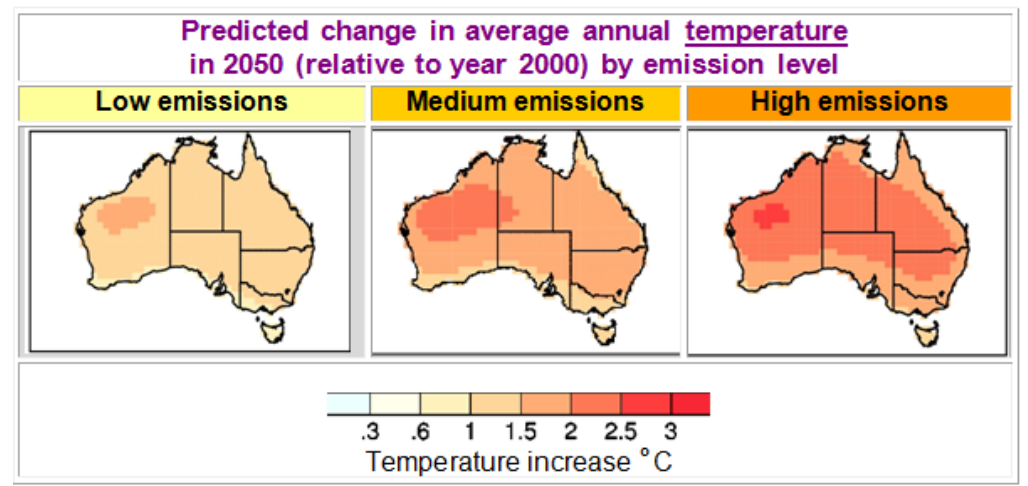

temperatures and decreased rainfall illustrated flow-on effects of climate change.

Figure 1 Temperature changes under the low, medium and high emissions scenario.

The second section of the survey consisted of an explanation of the choice experiment and the attributes appearing in each choice set. The statistical package Ngene was used to generate an orthogonal experimental design for the construction of the choice sets. An orthogonal design is a combination of alternatives which would allow the attribute levels to vary independent of one another, i.e. there is no correlation between the attributes (Bennett, 1999). By including the cost as one of the attributes, WTP for the attribute can be indirectly recovered from the people's choices (Hanley et al., 2001). The attributes and levels were identified through the literature review described, a series of focus groups and a pilot survey. The final list of attributes is presented in Table 1

Table 1 Attributes levels in the choice sets and coding

\begin{tabular}{|l|l|}
\hline Attribute & Levels \\
\hline \multirow{5}{*}{ Policy } & Carbon tax \\
\cline { 2 - 2 } & Petrol levy \\
\cline { 2 - 2 } & Electricity levy \\
\cline { 2 - 2 } & Income tax \\
\cline { 2 - 2 } & No policy to mitigate emissions (status quo) \\
\hline Use of tax revenue & Tax subsidies to lower income households \\
\cline { 2 - 2 } & Increase funding to public services \\
\cline { 2 - 2 } & Funding R\&D in climate change mitigation \\
\cline { 2 - 3 } & $100 \%$ for climate change mitigation \\
\cline { 2 - 3 } & No action (status quo) \\
\hline Emission level in 2050 & Low emission \\
\cline { 2 - 2 } & Medium emission \\
\cline { 2 - 2 } & High emission (status quo) \\
\hline Cost & $\$ 0$ (status quo) \\
\hline
\end{tabular}


$\$ 10, \$ 20, \$ 50, \$ 75, \$ 100, \$ 150$

In the choice sets, respondents were presented with a range of policy options to choose along with a "do nothing" option. Table shows a typical choice set presented in web format. Option 3 is identical in each experiment, representing a status quo alternative of no mitigation leading to high emission levels in 2050 - an alternative without any policy, use of tax revenues or costs. An example of the choice set as it appears in the questionnaire is in Table 2.

Table 2 Example of a choice set seen by participants of the internet survey

\begin{tabular}{|c|c|c|c|}
\hline 4 & Option 1 & Option 2 & $\begin{array}{c}\text { Option } 3 \\
\text { (Do nothing) }\end{array}$ \\
\hline Policy & Income tax & Electricity levy & $\begin{array}{l}\text { No policy to } \\
\text { mitigate emission }\end{array}$ \\
\hline $\begin{array}{l}\text { Use of tax revenue } \\
\text { from this policy }\end{array}$ & $\begin{array}{c}100 \% \text { for } \\
\text { climate change } \\
\text { mitigation }\end{array}$ & $\begin{array}{c}\text { Tax subsidies to } \\
\text { lower income } \\
\text { households }\end{array}$ & - \\
\hline $\begin{array}{l}\text { Monthly net cost to } \\
\text { you }\end{array}$ & $\$ 100$ & $\$ 150$ & $\$ 0$ \\
\hline $\begin{array}{l}\text { Emmission level in } \\
2050\end{array}$ & $\begin{array}{l}\text { Low } \\
\text { emission }\end{array}$ & $\begin{array}{l}\text { Low } \\
\text { emission }\end{array}$ & $\begin{array}{l}\text { Hiah } \\
\text { emission }\end{array}$ \\
\hline I choose: & ○ & O & O \\
\hline
\end{tabular}

The fourth and last section of the survey consisted of debriefing questions and questions on personal characteristics to capture and explain heterogeneity in responses. The debriefing questions were designed to check whether people had understood the survey and to identify protest votes and processing strategies like simplifying heuristics (Hess and Hensher, 2010). The first set of questions at the beginning of the survey asked respondents for their car use, petrol use and electricity use. Respondents who do not own any motor vehicle or do not pay for fuel (e.g. their fuel is fully subsidized by their employers) will be shown a value of $\$ 0$ for fuel levy in the choice experiment design. The second set of questions on demographics asked respondents for their sex, age, postcode, state of residence, property ownership, number of children, education and income. The third set of questions asked respondents for their climate change beliefs, environmentalist identity, political preference and their view on responsibility for climate change mitigation.

\subsection{Survey and sampling technique}

Respondents were recruited through an online research panel (database) where only participants over 18 years of age (of voting age) were asked to participate. Respondents received an invitation email to take part in the survey and after accepting the invitation to take part in the study, respondents were given a link to complete the survey.

\section{RESULTS}

A total of 103 usable questionnaires were obtained. The response rate was difficult to estimate for this panelbased survey, because it was not simply the proportion of those who responded to the initial invitation. Sample filters (such as excluding people under 18 years of age) and the fact that the online survey could have been closed when target numbers were achieved, irrespective of the willingness of potential respondents to complete the survey, made the calculation of the response rate problematic.

The conditional logit results presented in this paper were analysed using a specialised statistical software package, Stata 11. Table 3 presents the parameter estimates from the models. Respondents were separated into two groups based on their intentional vote in the next Federal election. The first group $(n=41)$ consists of participants who stated that they will vote for the Liberal party in the next election and the second group $(n=62)$ is non Liberal party voters. These two groups have several different preferences.

Firstly, the status quo variable is significant for both groups; however, Liberal party voters show a positive status quo effect while other non-Liberal party voters show a negative status quo effect. A positive coefficient on the status quo variable for Liberal party voters suggests a positive support for the government to 'do nothing' with regards to combating climate change. A negative status quo parameter for non-Liberal party voters implies an adverse preference towards do nothing.

Secondly, the carbon tax variable is significant for both groups; however, the coefficient is negative for Liberal party voters and positive for non-Liberal party voters. With income tax being used as a reference point, this 
implies that Liberal party voters are strongly averse to the carbon tax as compared to income tax, while nonLiberal party voters prefer carbon tax over income tax.

Thirdly, Liberal party voters are also strongly averse to petrol levies as compared to income tax, as indicated by significant and negative coefficient on the petrol levy variable, while non-Liberal party voters feel indifferent to this option when compared to income tax.

Fourthly, in terms of how the revenue generated is used, Liberal party voters prefer revenue to be used for subsidies to lower income households, as compared to using $100 \%$ of revenue for climate change mitigation. Non-liberal party voters on the other hand, strongly prefer that $100 \%$ of revenue is used for climate change mitigation over increasing funding to public services. In terms of emission target by year 2050, both groups showed no significant preference for low emissions over medium emissions.

Table 3 Parameter estimate from the conditional logit model

\begin{tabular}{|c|c|c|c|c|c|c|}
\hline & \multicolumn{3}{|c|}{ Liberal party voters } & \multicolumn{3}{|c|}{ Non-liberal party voters } \\
\hline $\mathbf{N}$ & \multicolumn{3}{|c|}{41} & \multicolumn{3}{|c|}{62} \\
\hline Log-likelihood & \multicolumn{3}{|c|}{-204.869} & \multicolumn{3}{|c|}{-394.728} \\
\hline & Coef. & Si. & Std.Err & Coef. & Si. & Std.Err \\
\hline Status quo & 0.9007 & $* * *$ & 0.3068 & -0.4679 & $* *$ & 0.2138 \\
\hline Monthly net cost & -0.0056 & * & 0.0031 & -0.0089 & *** & 0.0023 \\
\hline \multicolumn{7}{|l|}{ Policy } \\
\hline Carbon tax & -0.9741 & $* *$ & 0.4721 & 0.5814 & $* *$ & 0.2494 \\
\hline Petrol Levy & -1.0886 & ** & 0.4647 & 0.1732 & & 0.2387 \\
\hline Electricity levy & -0.3610 & & 0.4236 & 0.2858 & & 0.2603 \\
\hline \multicolumn{7}{|l|}{ Use of tax revenue } \\
\hline Increase funding to public services & 0.3425 & & 0.4217 & -0.6050 & *** & 0.2280 \\
\hline Tax subsidies to lower income households & 0.9930 & $* * *$ & 0.3694 & -0.0027 & & 0.2056 \\
\hline \multicolumn{7}{|l|}{ Emission level } \\
\hline Low emission & 0.1057 & & 0.2833 & 0.2351 & & 0.1939 \\
\hline
\end{tabular}

$*$ = significance at the $10 \%$ level, $* *=$ significance at the $5 \%$ level, $* * *=$ significance at the $1 \%$ level.

\section{CONCLUSION}

Findings from the pilot survey indicate that preferences for climate change mitigation policies and the use of revenues from such policies are salient issues to Australian households, despite a small sample size of only 103 respondents. These preferences appear to be split by people's voting intentions in the next election, Liberal voters versus non-Liberal voters. The next step for this study is to conduct a survey with a larger sample size, where more households are represented in the sample. 


\section{References}

Bateman, I. J., Carson, R. T., Day, B., Hanemann, W. M., Hanley, N., Hett, T., Jones-Lee, M., Loomes, G., Mourato, S., Özdemiroglu, E., Pearce, D. W., Sugden, R. \& Swanson, J. 2002. Economic valuation with stated preference techniques: A manual. Northampton: Edward Elgar.

Bennett, J. 1999. Some Fundamentals of Environmental Choice Modelling. Choice Modelling Research Reports. Canberra: University of New South Wales; No. 11.

Bennett, J. \& Blamey, R. (eds). 2001. The Choice Modelling Approach to Environmental Valuation. Cheltenham: Edward Elgar.

Berk, R. A. \& Fovell, R. G. 1999. Public perception of climate change: A 'willingness to pay' assessment. Climatic change, 41, 413-446.

Brouwer, R., Brander, L. \& Van Beukering, P. 2008. “A convenient truth”: Air travel passengers' willingness to pay to offset their $\mathrm{CO}_{2}$ emissions. Climatic Change, 90, 299-313.

Cai, B., Cameron, T. A. \& Gerdes, G. R. 2010. Distributional preferences and the incidence of costs and benefits in climate change policy. Environmental Resource Economics, 46, 429-458.

Carlsson, F., Kataria, M., Krupnick, A., Lampi, E., Lofgren, A., Qin, P., Chung, S \& Sterner, T. 2010. Paying for mitigation, a multiple country study. Environment for Development, 1-25.

Carson, R. T., Louviere, J. J. \& Wei, E. 2010. Alternative Australian climate change plans: The public's views. Energy Policy, 38, 902-911.

Dunlop, I. 2007. Prompt action required on sustainability and global inequity. ECOS, 138, 9-10.

Hanley, N., Mourato, S. \& Wright, R. 2001. Choice Modelling Approaches: A Superior Alternative for Environmental Valuation? Journal of Economic Surveys, 15(3), 435-462.

Hess, S. \& Hensher, D. A. 2010. Using conditioning on observed choices to retrieve individual-specific attribute processing strategies. Transportation Research Part B: Methodological, 44, 781-790.

Kanninen, B.J. 2006. Valuing environmental amenities using stated choice studies. Dordrecht: Springer.

Lee, J.J. \& Cameron, T. A. 2008. Popular support for climate change mitigation: Evidence from a general population mail survey. Environmental Resource Economics, 41, 223-248.

MacKerron, G. J., Egerton, C., Gaskell, C., Parpia, A. \& Mourato, S. 2009. Willingness to pay for carbon offset certification and co-benefits among young (high-) flying adults in the UK. Energy Policy, 37, 1372-1381.

McFadden, D. 1974. Conditional logit analysis of qualitative choice behavior, in: P. Zarembka (ed.), Frontiers of Econometrics. New York: Academic Press, 105-142. 